\title{
UV Absorption of Styrene Statistical Copolymers in Solution
}

\author{
Claudine NoËL and Lucien MonNerIE \\ Laboratoire de Physicochimie Structurale et Macromoléculaire \\ 10, rue Vauquelin 75231 PARIS-Cedex 05.
}

(Received October 11, 1975)

\begin{abstract}
Differences have been observed between the ultraviolet absorption of certain styrene statistical copolymers and that of the corresponding mixtures of homopolymers. These effects are a function of the chemical nature and position of the substituent on the benzene ring.

Analysis of the result obtained shows that the ultraviolet abscrption of styrene statistical copolymers depends on the tendency of the two monomeric units to be linked alternately along the binary copolymer chain and on the chain conformation, which in turn may favor or hinder, to a greater or lesser extent, electronic interactions between neighboring chromophore groups.

KEY WORDS Substituted Styrene-Styrene Random Copolymers / UV Absorption / Hypochromism /
\end{abstract}

The chemical composition of styrene statistical copolymers is often determined by UV spectroscopy by assuming that the UV extinction coefficients depend only on the total concentration of chromophore units. Earlier studies ${ }^{1,2}$ enabled us to show that this assumption is valid for the styrene-4-vinylpyridine and styrene- $p$-dimethylaminostyrene statistical copolymers. On the other hand, the random copolymers styrene-2-vinylpyridine, styrene2-methyl-5-vinylpyridine, and styrene-2-methyl6-vinylpyridine all present hyperchromic effects relative to both the corresponding block copolymers and the mixtures of homopolymers. ${ }^{3}$

It seemed to us that relationships might well exist between these hyperchromic effects and (a) the tendency of the two monomeric units to be linked alternately along the binary copolymer chain, (b) the steric hindrance due to substituents, and finally, (c) the chain conformation in solution.

To study the effects of these different parameters, we undertook the systematic analysis of the spectrophotometric properties of the ortho-, meta-, and para-substituted $\left(X=\mathrm{F}, \mathrm{Cl}, \mathrm{Br}, \mathrm{CH}_{3}\right)$ styrene-styrene statistical copolymers and the corresponding mixtures of homopolymers.

\section{EXPERIMENTAL}

After purification of the monomers (Fluka) by distillation under low-pressure nitrogen, the homopolymers and copolymers were prepared by free-radical polymerization, using $\alpha, \alpha^{\prime}$-azobisisobutyronitrile as the initiator. The polymerizations were performed in bulk, under vacuum at $60^{\circ} \mathrm{C}$. In each case the reaction was stopped when the monomer-polymer conversion rate approached $10 \%$. All samples were purified by successive dissolution in chloroform and precipitation in methanol, before being dried under vacuum $\left(10^{-2} \mathrm{~mm} \mathrm{Hg}\right)$ at $60^{\circ} \mathrm{C}$. The number-average molecular weights of all polymers were in the range 200,000-400,000.

The composition of the copolymers was determined by elemental analysis of the halogens. The styrene-methylstyrene copolymers were prepared from ${ }^{14} \mathrm{C}$ - $\beta$-styrene in order to evaluate their composition by liquid scintillation. This monomer was supplied, with a specific activity of $1.6 \mu \mathrm{Cu} / \mathrm{ml}$, by the labeled compounds division of the Centre d'Etudes Nucléaires at Saclay (France).

The UV spectra were traced in the wavelength range of $240-360 \mathrm{~nm}$ using a Cary 15 spectrophotometer. All the measurements were performed at a temperature of $25 \pm 0.1^{\circ} \mathrm{C}$. The solvent used was purified chloroform. The conditions of recording and the analysis of the spectra have been described previously. ${ }^{4}$ Molecular extinction coefficients have been deter- 


\section{NoËL and L. MONNERIE}

mined at the wavelengths corresponding to the absorption maxima of the substituted homopolystyrenes.

\section{RESULTS}

In each case, a mixture of polystyrene and substituted polystyrene showed the spectrum predicted from those of the two individual polymers by assuming that the UV absorption depends only on the concentration of the chromophore units. For all of the substituted styrene-styrene systems investigated, the frequencies of the absorption maxima were identical for the copolymer and the corresponding mixture of homopolymers.

Table I and Figures 1-5 show that, with the exception of the styrene- $p$-fluorostyrene system, the molecular extinction coefficients and the integrated intensities $(\sigma)$ of the statistical co-

Table I. Chromicity of substituted styrene-styrene random copolymers as a function of the substituent nature and position on the benzene ring

\begin{tabular}{|c|c|c|c|c|c|c|}
\hline \multirow[t]{2}{*}{$\begin{array}{l}\text { Nature and position } \\
\text { of the substituent } \\
\text { on the benzene } \\
\text { ring }\end{array}$} & \multirow[t]{2}{*}{$\begin{array}{c}\text { Substituted } \\
\text { styrene molar } \\
\text { content in the } \\
\text { copolymer, } \\
\%\end{array}$} & \multicolumn{2}{|c|}{$\begin{array}{l}\text { Area } \sigma, \mathrm{dm}^{2} \text {, under the } \\
\text { molecular extinction } \\
\text { coefficient } E \text { vs. wave- } \\
\text { length } \lambda \text { curve for } \\
\text { the copolymer }\end{array}$} & \multicolumn{2}{|c|}{$\begin{array}{l}\text { Area } \sigma, \mathrm{dm}^{2} \text {, under the } \\
\text { molecular extinction } \\
\text { coefficient } E \text { vs. wave- } \\
\text { length } \lambda \text { curve for the } \\
\text { homopolymer mixtures }\end{array}$} & \multirow{2}{*}{$\begin{array}{l}\text { Chromicity of } \\
\text { copolymers } \\
\text { relative to } \\
\text { corresponding } \\
\text { mixtures of } \\
\text { homopolymers, } \\
H^{\mathrm{b}} \times 10^{3}\end{array}$} \\
\hline & & $\lambda_{2}$ & $\sigma$ & $\lambda_{2}$ & $\sigma$ & \\
\hline $\mathrm{CH}_{3}$ & $\begin{array}{l}61.25 \\
48.6 \\
21.1\end{array}$ & $(300 \mathrm{~nm}-245 \mathrm{~nm})$ & $\begin{array}{l}586 \\
567 \\
475\end{array}$ & $(300 \mathrm{~nm}-245 \mathrm{~nm})$ & $\begin{array}{l}580 \\
546 \\
472\end{array}$ & $\begin{array}{l}-10 \\
-38 \\
-6\end{array}$ \\
\hline $\mathrm{CH}_{3}$ & $\begin{array}{l}65.4 \\
26.45\end{array}$ & & $\begin{array}{l}520 \\
451\end{array}$ & & $\begin{array}{l}514 \\
455\end{array}$ & $\begin{array}{l}-11 \\
+9\end{array}$ \\
\hline para & $\begin{array}{l}66.2 \\
19\end{array}$ & & $\begin{array}{l}683 \\
494\end{array}$ & & $\begin{array}{l}680 \\
492\end{array}$ & $\begin{array}{l}-4 \\
-4\end{array}$ \\
\hline ortho & $\begin{array}{l}67.7 \\
50.1 \\
35.9\end{array}$ & $(300 \mathrm{~nm}-240 \mathrm{~nm})$ & $\begin{array}{r}1180 \\
1034 \\
840\end{array}$ & $(300 \mathrm{mn}-240 \mathrm{~nm})$ & $\begin{array}{r}1168 \\
981 \\
830\end{array}$ & $\begin{array}{l}-10 \\
-54 \\
-13\end{array}$ \\
\hline para & $\begin{array}{l}71.2 \\
36.5 \\
19.4\end{array}$ & & $\begin{array}{r}1250 \\
867 \\
673\end{array}$ & & $\begin{array}{r}1236 \\
852 \\
662\end{array}$ & $\begin{array}{l}-11 \\
-17 \\
-16\end{array}$ \\
\hline ortho & $\begin{array}{l}73.0 \\
53.2 \\
31.1 \\
21.0\end{array}$ & $(300 \mathrm{~nm}-248 \mathrm{~nm})$ & $\begin{array}{l}511 \\
488 \\
457 \\
440\end{array}$ & $(300 \mathrm{~nm}-248 \mathrm{~nm})$ & $\begin{array}{l}514 \\
477 \\
445 \\
428\end{array}$ & $\begin{array}{l}+5 \\
-23 \\
-26 \\
-28\end{array}$ \\
\hline meta & $\begin{array}{l}70.0 \\
57.0 \\
35.8 \\
20.8\end{array}$ & & $\begin{array}{l}515 \\
491 \\
452 \\
427\end{array}$ & & $\begin{array}{l}511 \\
487 \\
453 \\
428\end{array}$ & $\begin{array}{l}-7 \\
-8 \\
+2 \\
+3\end{array}$ \\
\hline para & $\begin{array}{l}79.7 \\
64.6 \\
49.7 \\
33.6\end{array}$ & & $\begin{array}{l}681 \\
624 \\
568 \\
509\end{array}$ & & $\begin{array}{l}676 \\
620 \\
568 \\
512\end{array}$ & $\begin{array}{r}-7 \\
-6 \\
0 \\
+5\end{array}$ \\
\hline ortho & $\begin{array}{l}55.5 \\
49.3 \\
32.9\end{array}$ & $(300 \mathrm{~nm}-250 \mathrm{~nm})$ & $\begin{array}{l}457 \\
452 \\
420\end{array}$ & $(300 \mathrm{~nm}-250 \mathrm{~nm})$ & $\begin{array}{l}443 \\
434 \\
411\end{array}$ & $\begin{array}{l}-31 \\
-40 \\
-22\end{array}$ \\
\hline meta & $\begin{array}{l}56.3 \\
48.2 \\
28.10\end{array}$ & & $\begin{array}{l}475 \\
460 \\
421_{4}\end{array}$ & & $\begin{array}{l}479 \\
463 \\
421_{8}\end{array}$ & $\begin{array}{r}+8 \\
+6 \\
0\end{array}$ \\
\hline
\end{tabular}

a $\sigma=\int_{\lambda_{1}}^{\lambda_{2}} \frac{O \cdot D_{\lambda}}{l c} \mathrm{~d} \lambda=\int_{\lambda_{1}}^{\lambda_{2}} E_{\lambda} \mathrm{d} \lambda$

b $H=1-\frac{\sigma_{\text {copolymer }}}{\sigma_{\text {homopolymer mixture }}}$
$O . D_{\lambda}$, optical density at $\lambda ; c$, concentration in mol/l; $l$, length of absorbing path in $\mathrm{cm} ; \lambda$, wavelength in $\mathrm{nm} ; E$, molecular extinction coefficient.

A hyperchromic effect corresponds to a negative value for $H$. 
UV Absorption of Styrene Statistical Copolymers in Solution

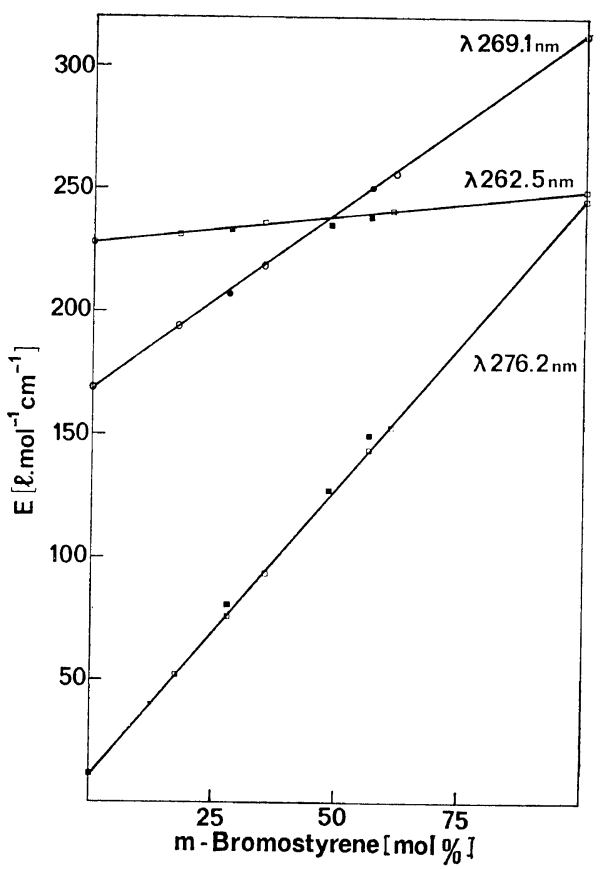

Figure 1. Molecular extinction coefficients as a function of $m$-bromostyrene molar content:

O, styrene- $m$-bromostyrene random copolymers; $\square, \bigcirc$, mixtures of polystyrene and poly $(m$-bromostyrene).

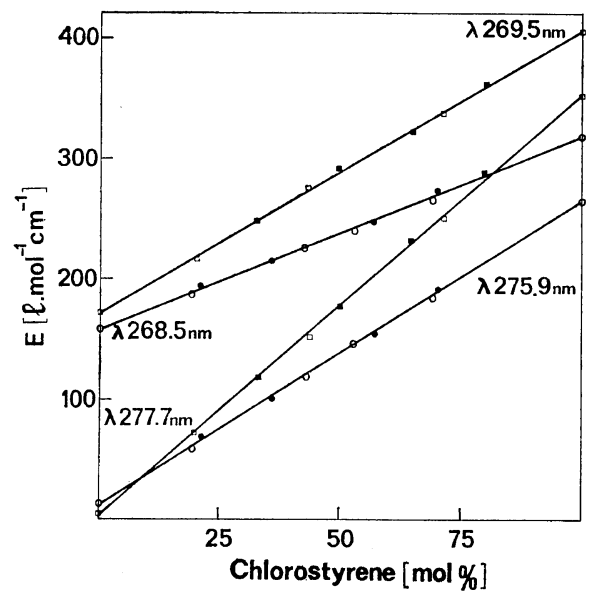

Figure 2. Molecular extinction coefficients as a function of $p$ - or $m$-chlorostyrene molar content: $\square$, styrene- $p$-chlorostyrene random copolymers; $\square$, mixtures of polystyrene and poly( $p$-chlorostyrene); 0 , styrene- $m$-chlorostyrene random copolymers; $\bigcirc$, mixtures of polystyrene and poly $(m-$ chlorostyrene). polymers of styrene and para- or meta- substituted styrene are similar to those of the corresponding mixtures of homopolymers (Figures

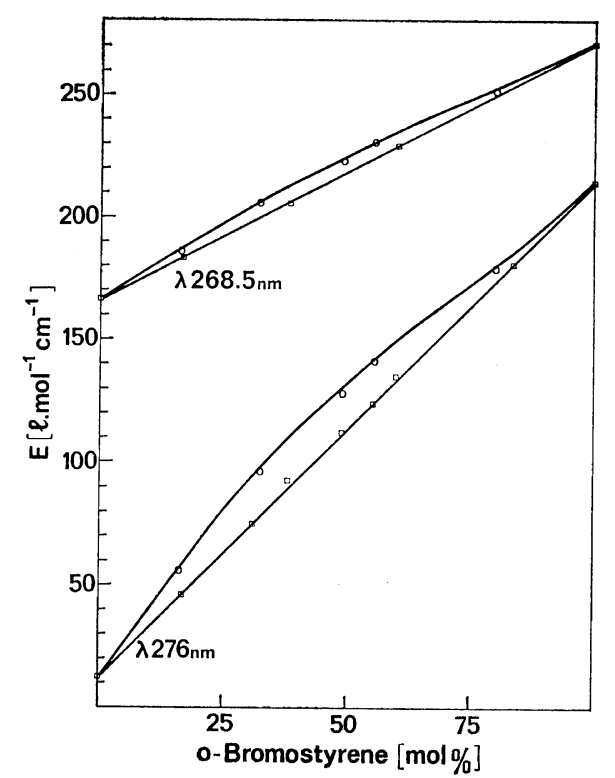

Figure 3. Molecular extinction coefficients as a function of $o$-bromostyrene molar content: $O$, styrene-o-bromostyrene random copolymers; $\square$, mixtures of polystyrene and poly(o-bromostyrene).

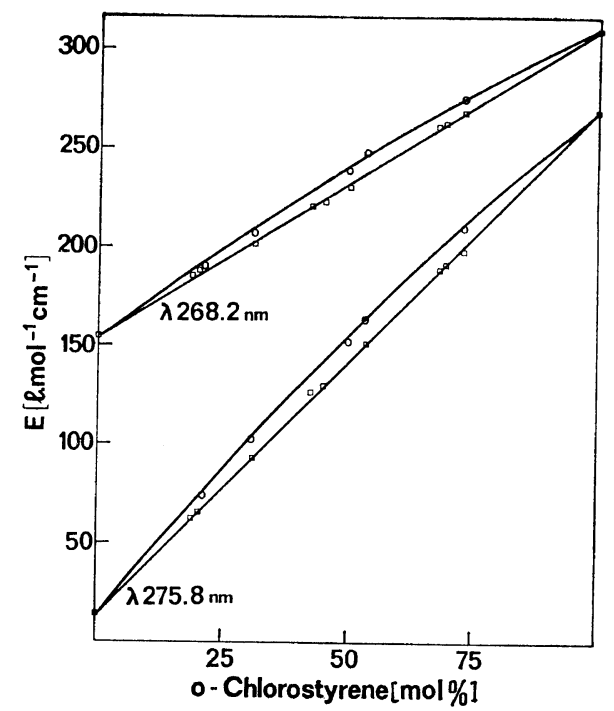

Figure 4. Molecular extinction coefficients as a function of $o$-chlorostyrene molar content: $\bigcirc$, styrene-o-chlorostyrene random copolymers; $\square$, mixtures of polystyrene and poly(o-chlorostyrene). 


\section{NoËL and L. MonNerie}

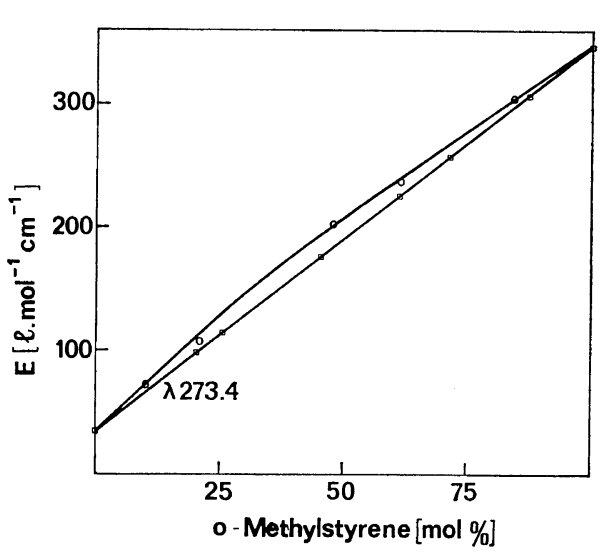

Figure 5. Molecular extinction coefficients at $273.4 \mathrm{~nm}$ as a function of $o$-methylstyrene molar content: $\bigcirc$, styrene-o-methylstyrene random copolymers; $\square$, mixtures of polystyrene and poly $(o-$ methylstyrene).

1 and 2). On the contrary, the statistical copolymers of the ortho-substituted derivatives present a slight degree of hyperchromism (Figures 3-5). These effects depend on the substituent steric hindrance and become progressively more pronounced for the sequence $\mathrm{F}<\mathrm{Cl}, \mathrm{CH}_{3}<\mathrm{Br}$. Moreover, the magnitude of the observed hyperchromism depends on copolymer composition and, in general, is maximum for equimolar copolymers.

\section{DISCUSSION}

Effects similar to those just described have been reported previously both by the present authors for styrene-vinylpyridine system $\mathrm{s}^{1-3}$ and by other workers for different copolymers. ${ }^{5-13}$

Analysis of our results and the literature data shows that the statistical copolymers styrenepara-substituted styrene and styrene-meta-substituted styrene $e^{1,6-8}$ behave in the same way as the corresponding mixtures of homopolymers. However, if the two constituent monomers differ in their chemical nature $e^{2,3,5,9,11-13}$ or, if one of the two is substituted in the ortho-position relative to the main chain, ${ }^{3,9,10}$ then the statistical copolymers will be either hyper- or hypochromic.

In most cases, ${ }^{2,3,5,9,12,13}$ the magnitude of the chromicity phenomena involved varies with the composition of the copolymers, and tends to a maximum for equimolar ones. Besides, Stützel, et $a l .{ }^{5}$ have shown that the degree of hypochromism presented by alternating copolymers of styrene and methyl methacrylate is higher than for the corresponding equimolecular statistical forms. Such effects clearly indicate the marked influence of the primary structure of the copolymer on the UV absorption. The data available in the literature reveal that for the majority of copolymers for which the absorption spectrum is significantly different from that of the corresponding mixture of homopolymers, the product of the monomer reactivity ratios, $r_{1} \cdot r_{2}$, has a very low value. This implies the existence of numerous long sequences of alternating monomer units (ABAB...), which may either favor the establishment of electronic interactions between $\mathrm{A}$ and $\mathrm{B}$ chromophore units or, on the contrary, lead to the destruction of any interactions that might have been set up in one of the homopolymers.

However, for the styrene-2-vinylpyridine, styrene-2-methyl-5-vinylpyridine, and the styrene-o-methyl, - $o$-chloro, and - o-bromostyrene systems, the product $r_{1} \cdot r_{2}$ is too large $(>0,5)$ to account for the observed hyperchromism. Thus it would seem that, for these systems, the hyperchromicity should be attributed to differences between the chain conformations of the copolymer and the corresponding homopolymers, rather than to the monomerunit distribution law.

The calculation of the potential energies ${ }^{14}$ of (a) the dimers of substituted polystyrenes and poly(vinylpyridine)s and (b), the model compounds of both the ortho-substituted styrene-styrene and styrene-2-vinylpyridine alternating copolymers has shown that steric hindrance is the principal factor determining the equilibrium conformation and mobility of these molecules.

Thus a para-aromatic ring substitution affects neither the predicted most stable conformations of 2,4-diphenylpentane nor their energies. This behavior tends to suggest that the conformations of the para-substituted styrene-styrene copolymers in solution should be very similar to those of the homopolymers. This result, which is related to the fact that the direction of the transition moment is the same for polystyrene and its para-substituted derivatives, ${ }^{4}$ accounts 
for the fact that the observed absorptions of the para-substituted styrene-styrene copolymers are identical to those of the corresponding mixtures of homopolymers.

The effects of a meta-substitution are rather weak. On the contrary, an ortho-aromatic ring substitution modifies the equilibrium conformations. The extent of these modifications is directly dependent on the substituent steric hindrance and is generally sufficient to imply not only that the most stable helical structure of the ortho-substituted polystyrenes changes relative to the $3_{1}$ helix of isotactic polystyrene, but also that the conformations of the ortho-substituted styrene-styrene copolymers differ from those of the corresponding homopolymers. As a result of these conformational changes, the electronic interactions between chromophore groups may be different in the statistical copolymers and in the homopolymers. Such differences can account for the observed hyperchromism of these systems (Figures 3-5).

\section{CONCLUSION}

The comparative study, using UV spectrophotometry, of the substituted styrene-styrene statistical copolymers and the corresponding mixtures of homopolymers has enabled us to establish the existence of differences of chromicity, the magnitude of which depends on the nature and position of the substituent on the benzene ring.

Analysis of our results and the data available in the literature tends to suggest that the spectrophotometric properties of the statistical copolymers in question depend not only on the direction of the transition moments of the chromophores but also on the distribution of the monomer units along the copolymer chain and on the copolymer chain conformation. The latter may differ from that of the homopolymer and thus either favor the establishment of electronic interactions between neighboring chromophore groups or, on the contrary, lead to the destruction of any interactions that might have been set up in the homopolymers.

\section{REFERENCES}

1. C. Noël and L. Monnerie, C.R. Acad. Sci. Paris, C, 260, 5270 (1965).

2. C. Noël and L. Monnerie, J. Chim. Phys. 65, 2096 (1968).

3. C. Schneider, C. Noël, and L. Monnerie, C.R. Acad. Sci. Paris, C, 265, 703 (1967).

4. F. Gény, C. Noël, and L. Monnerie, J. Chim. Phys., 71, 1150 (1974).

5. R. Stützel, T. Miyamoto, and H. J. Cantow, IUPAC, Helsinki, Preprints, 3, 337 (1972).

6. H. W. Melville and L. Valentine, Trans. Faraday Soc., 51, 1474 (1955).

7. B. D. Phillips, T. L. Hanlon, and A. V. Tobolsky, J. Polym. Sci., Part A, 2, 4231 (1964).

8. W. Kern and D. Braun, Makromol. Chem., 27, 23 (1958).

9. H. Kamogawa and H. G. Cassidy, J. Polym. Sci., Part A, 1, 1971 (1963).

10. H. Kamogawa and H. G. Cassidy, ibid., Part A, 2, 2409 (1964).

11. A. Gascoin, "Etude par spectrométrie d'absorption des copolymères méthacrylate de méthyle-styrène", Extrait Lacq Mai 1966.

12. R. J. Brüssau and D. J. Stein, Angew. Makromol. Chem., 12, 59 (1970).

13. B. Gallo and S. Russo, J. Macromol. Sci.-Chem., A8, 521 (1974).

14. S. Gorin and L. Monnerie, J. Chim. Phys. 67, $869,878,885$ (1970). 